\title{
A novel strain of Lactobacillus mucosae isolated from a Gaotian villager improves in vitro and in vivo antioxidant as well as biological properties in D-galactose-induced aging mice
}

\author{
Xiaomin Yu, ${ }^{*} \dagger$ Shengjie Li, ${ }^{*} † \ddagger$ Dong Yang, ${ }^{*} \dagger$ Liang Qiu, ${ }^{*} \dagger$ Yaoping Wu, ${ }^{*} \dagger$ Dengyuan Wang, ${ }^{*} \dagger$ \\ Nagendra P. Shah,§ Feng $X u,{ }^{* 1}$ and Hua Wei* ${ }^{1}$ \\ *State Key Laboratory of Food Science and Technology, Nanchang University, Nanchang, Jiangxi, 330047, P. R. China \\ †Jiangxi-OAI Joint Research Institute, Nanchang University, 235 Nanjing Donglu, Nanchang, Jiangxi, 330047, P. R. China \\ łInstitute of Applied Agricultural Microbiology, Jiangxi Academy of Agricultural Sciences, 602 Nanlian Road, Nanchang, Jiangxi 330200, \\ P. R. China \\ §Food and Nutritional Science, School of Biological Science, The University of Hong Kong, Pokfulam Road, Hong Kong, P. R. China
}

\begin{abstract}
Twelve isolates isolated from the gastrointestinal tracts of Gaotian villagers in China, who had a lifespan of $92 \mathrm{yr}$, were examined for their antioxidants using free radical scavenging activity and 2,2-diphenyl-1-picrylhydrazyl. Three strains (i.e., Lactobacillus mucosae LMU1001, and Lactobacillus plantarum LPL0902 and LPL0302) were selected as candidates to prepare yogurt for testing their antioxidants in a model of D-galactoseinduced aging mice, with vitamin $\mathrm{C}$ as a positive control. The results showed that L. mucosae LMU1001 was the best strain, which had similar in vivo antioxidant activity as vitamin C. A significant increase was found in the activities of glutathione peroxidase in serum and total superoxide dismutase in the liver, and a decrease in the level of malondialdehyde in serum. Regarding mRNA expression level detected quantitatively by real-time PCR, we observed that L. mucosae LMU1001 significantly upregulated antioxidant genes (i.e., MT1A and MT1M in HT-29 and Caco-2) and those genes (i.e., MT1, MT2, GPx1, and GPx2) in the intestinal tract of the model mice. Hence, this strain could be considered as a potential probiotic lactic acid bacterium for improving antioxidant levels in functional foods.
\end{abstract}

Key words: antioxidant activity, 2,2-diphenyl-1picrylhydrazyl, hydroxyl radical, reducing power, D-galactose-induced aging mice

\section{INTRODUCTION}

It has been suggested that longevity may be related to many factors, such as heredity (Deelen et al., 2014), environment (Prather et al., 2015), and constitution

Received August 16, 2015.

Accepted October 19, 2015.

${ }^{1}$ Corresponding authors: weihua114@live.cn and ziwu211@126.com of gut flora (Biagi et al., 2015), or even some special bacterial species. In the last decade, some researchers focused on the global microbiota analysis of people with longevity (Zhao et al., 2011). Probiotics including Lactobacillus and Bifidobacterium have attracted much attention due to their role in health promotion. Healthy people, especially with longevity, were the main target for isolating probiotics all over the world (Woo et al., 2014). Bifidobacterium longum ssp. longum BBMN68 isolated from healthy centenarians in Bama, China, was reported to enhance immune function in $\mathrm{BALB} / \mathrm{c}$ mice (Yang et al., 2009). Similar to Bama and other areas of people with longevity, the Gaotian village, located in Liuyang city of Hunan province in the middle-south of China, boasts people with a lifespan of up to $92 \mathrm{yr}$ with no history of chronic diseases. However, the microbial community of those people has not been studied so far and the reasons for their longevity are still unknown. Therefore, a systematic study of the microflora of the Gaotian villager is of utmost importance to understand a relationship between the constituents of microflora and health status.

Recently antioxidant potential of lactic acid bacteria (LAB) and their components (e.g., exopolysaccharides and proteins) was frequently reported and even regarded as one of the standard for evaluation of probiotic functions (Li et al., 2014a; Li and Shah, 2014). Evaluation of antioxidant properties includes in vitro oxidation reaction system and in vivo animal testing; the former covers a series of protocols for scavenging free radicals, chelating metal ions, and inhibiting lipid peroxidation (Makarova et al., 2006), whereas the latter covers monitoring change in the antioxidant enzyme system [i.e., glutathione peroxidase, superoxide dismutase, and malondialdehyde (MDA)] content of host (LeBlanc et al., 2011). Zhang et al. (2010) used a hyperlipidemic model rat, which was induced by a high-fat diet, to test antioxidant properties, and demonstrated that 
Lactobacillus casei Zhang alleviated oxidative stress by reducing lipid peroxidation, and improved lipid metabolism both in blood and liver of the rat. Kanno et al. (2012) reported that Lactobacillus plantarum 7FM10 from the traditional Japanese food narezushi exhibited 2,2-diphenyl-1-picrylhydrazyl (DPPH) and superoxide radical scavenging capabilities (Kanno et al., 2012).

To date, several reports pertaining to antioxidant evaluation of LAB have been published; however, a systematic evaluation of the antioxidant mechanism from cell lines to model mice, from metabolic substances to the gene expression level, has not been reported yet.

In our previous study ( $\mathrm{Yu}$ et al., 2015), the gut microbial community of long-living elderly residents of a Gaotian village was analyzed systematically using $16 \mathrm{~S}$ high-throughput sequencing, and 12 of 82 isolates were screened and studied for their probiotic and biological characteristics (data not shown). To obtain an overview of the functional properties of the potential strains, in this study, we first investigated their antioxidant capability. Second, we investigated the effects of yogurt on the physiological and biochemical index of serum and organ by using D-galactose (D-Gal)-induced aging mice. Subsequently, we examined the antioxidant mechanisms of selective LAB strains in cell lines of HT-29 and Caco-2. Some important host oxidant genes (i.e., MT1, MT2) and enzyme (i.e., SOD, GSH-PX) were quantitatively detected with the aid of biochemical analysis and real-time PCR technique.

\section{MATERIALS AND METHODS}

\section{Bacteria Strains and Culture}

Twelve strains isolated from the intestinal tract of long-living elderly residents of a Gaotian village of Liuyang City, Hunan, China, including L. plantarum LPL0105, LPL0302, and LPL0902, L. fermentum LFE0608, LFEP3, and LFEP6, L. salivarius LSAP2 and LSAP5, L. mucosae LUM1001, Enterococcus hirae P1, and Enterococcus faecalis $\mathrm{P} 4$, were used in this study. All the strains were cultured anaerobically in de Man, Rogosa, Sharpe broth (MRS; Beijing Solarbio Science and Technology Co. Ltd., Beijing, China) medium at $37^{\circ} \mathrm{C}$ for $18 \mathrm{~h}$.

\section{Preparation of Cells, Supernatants of Different Strains, and Yogurt}

Cells of 12 strains were harvested by centrifugation (Thermo Fisher Sorvall ST 16R, Schwerte, Germany) at $4^{\circ} \mathrm{C}, 8,000 \times g$, for $10 \mathrm{~min}$ after culturing anaerobically in $50 \mathrm{~mL}$ of MRS broth $(1 \%, \mathrm{vol} / \mathrm{vol})$ at $37^{\circ} \mathrm{C}$ for $18 \mathrm{~h}$.
The supernatants were decanted. The cell pellets were then washed in triplicates in PBS and resuspended in $50 \mathrm{~mL}$ of PBS. For preparation of yogurt using the 12 strains, $100 \mathrm{~mL}$ of skim milk was inoculated with $1 \%$ of overnight culture of each strain and then incubated anaerobically at $37^{\circ} \mathrm{C}$ for $24 \mathrm{~h}$. Both cells and supernatants of 12 strains, and 12 batches of yogurt, were stored at $4^{\circ} \mathrm{C}$ for use.

\section{Antioxidant Activity by Scavenging DPPH Free Radical}

The DPPH free radical scavenging activity was determined according to the method of $\mathrm{Li}$ and Shah (2014). Briefly, $0.2 \mathrm{mM}$ DPPH (Sigma Chemical Co.) solution in $100 \mathrm{~mL}$ of ethanol was prepared, $1.0 \mathrm{~mL}$ of each sample and ethanol as control were mixed with $4.0 \mathrm{~mL}$ of ethanolic DPPH solution, respectively, and incubated in the dark for $30 \mathrm{~min}$. The blank was 4.0 $\mathrm{mL}$ of ethanol mixed with $1.0 \mathrm{~mL}$ of MRS or PBS. The absorbance of supernatant was measured at 517 $\mathrm{nm}$ after centrifugation at room temperature $\left(23^{\circ} \mathrm{C}\right)$ at $4,500 \times g$ for $10 \mathrm{~min}$. The scavenging of DPPH radical was calculated as follows: scavenging ability $(\%)=100$ $-\left(\mathrm{A}_{\text {sample }}-\mathrm{A}_{\text {blank }}\right) / \mathrm{A}_{\text {control }} \times 100$.

\section{Antioxidant Activity by Scavenging Hydroxyl Radical}

The scavenging activity of hydroxyl radical was determined by a Fenton reaction method (Ferreira et al., 2007; Arasu et al., 2014). Briefly, the reaction mixture contained $1.0 \mathrm{~mL}$ of PBS (0.02 mM, pH 7.4), $0.5 \mathrm{~mL}$ of 1,10-phenanthroline monohydrate $(2.5 \mathrm{mM}), 0.5$ $\mathrm{mL}$ of $\mathrm{FeSO}_{4}(2.5 \mathrm{mM})$, and $0.5 \mathrm{~mL}$ of $\mathrm{H}_{2} \mathrm{O}_{2}(20 \mathrm{mM})$. The mixture was mixed with $0.5 \mathrm{~mL}$ of each sample, and maintained at $37^{\circ} \mathrm{C}$ for $1 \mathrm{~h}$. The absorbance of the mixture was measured at $536 \mathrm{~nm}$ and the equation of hydroxyl radical scavenging activity is expressed as follows: scavenging ability $(\%)=\left[\left(\mathrm{As}-\mathrm{A}_{\mathrm{o}}\right) /\left(\mathrm{A}-\mathrm{A}_{\mathrm{o}}\right)\right]$ $\times 100$, where As is the absorbance of tested sample, $\mathrm{A}_{\mathrm{o}}$ is the absorbance of the control, and the $\mathrm{A}$ is the absorbance without sample and $\mathrm{H}_{2} \mathrm{O}_{2}$.

\section{Reducing Power}

Detection of reducing power was carried out according to the method of Marazza et al. (2012), with minor modifications. Briefly, an aliquot of $0.5 \mathrm{~mL}$ of the sample was mixed with $0.5 \mathrm{~mL}$ of PBS $(0.2 \mathrm{M}$, pH 6.6) and $0.5 \mathrm{~mL}$ of $0.1 \%$ potassium ferric cyanide and mixed. The mixed solution was added with the same volume of $10 \%$ trichloroacetic acid to stop the reaction after incubation at $50^{\circ} \mathrm{C}$ for $20 \mathrm{~min}$. This was followed 
by mixing $0.1 \mathrm{~mL}$ of ferric chloride $(0.1 \%)$ with the supernatants, which was obtained after centrifugation at $4^{\circ} \mathrm{C}, 3,000 \times g$ for $10 \mathrm{~min}$. After reaction for $10 \mathrm{~min}$, the absorbance of the solution measured at $700 \mathrm{~nm}$. Higher absorbance means higher reducing power.

\section{Animals and Animal Experiments}

The protocol for the animal experiment was approved by Nanchang University Animal Ethical Committee and met all ethical requirements to conduct the experiment (approval number 0064257).

Sixty 5-wk-old BALB/c male mice were purchased from Animal Center of Nanchang University (Jiangxi, China). Mice were initially acclimatized to the laboratory conditions for $10 \mathrm{~d}$, then housed at $23 \pm 1^{\circ} \mathrm{C}, 12: 12$ $\mathrm{h}$ light-dark cycle. They were divided into 6 groups (10 in each group) at random, including 5 groups that were injected subcutaneously with D-Gal at $50 \mathrm{mg} / \mathrm{kg} \cdot \mathrm{d}$ BW (Song et al., 1999) and a sixth group that was injected subcutaneously with equivalent physiological saline as a control. After $30 \mathrm{~d}, 3$ groups were administered via gastric gavage with fermented yogurt by 3 strains, the fourth group was gavaged with skim milk as a D-Gal model group, and the fifth group was gavaged with vitamin C, which served as a positive control. The sixth group was administered via gastric gavage with an equivalent volume of skim milk and served as the negative control. The BW was recorded after narcosis with ethyl ether, and the blood (potassium EDTA collection tube) was collected from the orbital sinus by quickly removing the eyeball. The tissue of mice was weighed and recorded after dissection.

\section{Biochemical Analysis}

The serum of the mice was prepared by storing the whole blood at $4^{\circ} \mathrm{C}$ overnight and centrifuged (Thermo Fisher Sorvall ST $16 \mathrm{R}$ ) at $4^{\circ} \mathrm{C}, 2,000 \times g$ for $8 \mathrm{~min}$. For evaluation of antioxidant activity, the levels of glutathione peroxidase (GSH-PX), total superoxide dismutase (T-SOD), and MDA in the serum and liver were determined according to the instructions of kits (Nanjing Jiancheng Bioengineering Institute, Nanjing, China). For evaluation of biochemical index, alanine transaminase (ALT), aspartate aminotransferase (AST), total bilirubin (TBIL), direct bilirubin (DBIL), creatinine (CREA), urea and uric acid (UA), blood glucose (GLU), triglyceride (TG), and total cholesterol (TCHOL) were tested in the First Affiliated Hospital of Nanchang University (Ceriotti et al., 2010; Coban et al., 2014; Schulkens et al., 2014). Spleens, kidneys, hearts, and livers were weighed, and the organ index was estimated from the ratio of organ weight to $\mathrm{BW}$ (organ weight/BW $\times 100$ ).

\section{Cell Lines and Tests}

The human colon carcinoma cell lines HT-29 and Caco-2 were cultured on Petri dishes in Dulbecco's modified Eagle's medium (DMEM, Gibco, Grand Island, NY) with $10 \%$ FBS (Gibco), and propagated at $37^{\circ} \mathrm{C}$ under $5 \% \mathrm{CO}_{2}$. Fresh overnight cultures of tested strains, after washing triplicates with PBS, were incubated with 2 cells of Caco-2 and HT-29, respectively, in $4 \mathrm{~mL}$ of DMEM at $37^{\circ} \mathrm{C}$ under $5 \% \mathrm{CO}_{2}$ for $2 \mathrm{~h}$. The ratio of cells of Caco-2 and HT-29 to that of tested strains was 1:10.

\section{RNA Isolation and cDNA Synthesis}

Total RNA was isolated according to the instructions of TaKaRa MiniBEST Universal RNA extraction kit (Takara Bio, Dalian, China). Five micrograms of total RNA was transcribed into cDNA according to the instructions of the PrimeScript 1st Strand cDNA Synthesis Kit (Takara Bio).

\section{Real-Time PCR}

The standard curve was used for quantification between the housekeeping gene and the reference gene. The PCR primers of intestine of mice are listed in Table 1, and the cell lines are listed in Table 2. Quantitative PCR amplification was performed using the ABI 7900 HT fast real-time PCR system (Applied Biosystems, Foster City, CA). The reaction of real-time PCR assays contained $10 \mu \mathrm{L}$ of SYBR Primer EX TaqII (Takara Bio), $0.75 \mu \mathrm{L}$ each of the primers with $1 \mu \mathrm{L}$ cDNA template and $7.5 \mu \mathrm{L} \mathrm{H}_{2} \mathrm{O}$, and the final volume of 20 $\mu \mathrm{L}$. The amplification was programed to start at $95^{\circ} \mathrm{C}$ for $5 \mathrm{~min}$, followed by 40 cycles of $95^{\circ} \mathrm{C}$ for $30 \mathrm{~s}, 60^{\circ} \mathrm{C}$ for $30 \mathrm{~s}$, and $72^{\circ} \mathrm{C}$ for $30 \mathrm{~s}$. The template of cDNA was run in triplicate by real-time PCR and analyzed using the $2^{-\Delta \Delta \mathrm{Ct}}$ method based on RT-PCR data as described by Feng et al. (2010).

\section{Statistical Analysis}

All tests were carried out in triplicate for all the experiments. All data were expressed as means \pm standard deviation of 3 parallel tests. The SPSS version 14.0 software was used for statistical analyses (SPSS Inc., Chicago, IL) by means of independent one-way ANOVA tests. The figures were prepared by using 
Table 1. The PCR primers related to oxidative stress in real-time PCR on the intestine of mice

\begin{tabular}{lll}
\hline $\begin{array}{l}\text { Gene } \\
\text { name }^{1}\end{array}$ & Forward primer $\left(5^{\prime}-3^{\prime}\right)$ & \\
\hline$M T 1$ & TTCACCAGATCTCGGAATGG & Reverse primer $\left(5^{\prime}-3^{\prime}\right)$ \\
MT2 & CCTGCAAATGCAAACAATGC & CACTTGTCACTTGCAGTTCTTG \\
GPx1 & TGAGAAGTGCGAGGTGAATG & CGGGGACCAAATGATCTTTG \\
GPx2 & TGCCCTACCCTTATGACGAC & TCGATGTTGATGGTCTGGAA \\
SOD & CGAGGGGCATCTAGTGGAGAAG & TTAGGGCTCAGGTTTGTCCAGAA \\
$\beta$-Actin & AGGCCAACCAACCGCGAGAAG & GTCCAGGCGCATGATGG \\
\hline
\end{tabular}

${ }^{1} M T 1=$ metallothionein 1; MT2 = metallothionein 2; GPx1 = glutathione peroxidase 1; GPx2 = glutathione peroxidase $2 ; S O D=$ superoxide dismutase.

GraphPad Prism 5.0 software (GraphPad Software Inc., La Jolla, CA).

\section{RESULTS}

\section{In Vitro Tests for Antioxidant Ability of Cells, Supernatants of Isolates, and Yogurt Made by Using Those Isolates}

Twelve isolates of villagers from Gaotian, China, with a history of long lifespan were determined by $16 \mathrm{~S}$ rDNA, and 10 of the isolates were classified as Lactobacillus, whereas 2 of the isolates were classified as Enterococcus. Further, those strains were investigated for their antioxidant ability based on the scavenging of DPPH free radicals and hydroxyl radicals, and total reducing power. Considering the contribution of antioxidant potential might come from either cells or the supernatants, a series of systematic tests was performed for evaluation of the potential application of those strains in a dairy product (e.g., yogurt). For scavenging of DPPH free radicals (Figure 1A), the behavior of cells, supernatants, and yogurt was different among 12 strains; L. mucosae LMU1001, L. plantarum LPL0902 and LPL0302, and L. fermentum LFE1014 demonstrated relatively higher scavenging ability in all the indices (i.e., cell counts, supernatants, and yogurt); namely, their DPPH free radical scavenging ability of cells, supernatants of isolates, and yogurt exceeded $60 \%(72.78,63.28$, and $88.15 \%$ vs. $69.50,75.00$, and
$71.39 \%$ vs. $66.25,64.75$, and $75.56 \%$ vs. $64.50,67.30$, and $68.13 \%$, respectively). For scavenging of hydroxyl radicals (Figure 1B), in general, supernatants demonstrated the highest scavenging activities, at $88.25 \%$, $83.36 \%$, and $86.28 \%$ for L. fermentum LFE0608, L. mucosae LMU1001, and L. salivarius LSAP2, respectively. Similar results were achieved for reducing power tests (Figure 1C); the reducing power of supernatants was the best among tests for cell counts, supernatants of isolates, and their yogurt product. The highest reducing power was from the strain of L. mucosae LMU1001 (optical density at $700 \mathrm{~nm}=2.021$ ).

Based on the comprehensive results of scavenging of DPPH free radical and hydroxyl radical, and total reducing power of 12 strains, L. mucosae LMU1001 and L. plantarum LPL0302 were selected for their enhanced antioxidant ability in yogurt and L. plantarum LPL0902 for their average antioxidant ability in cells, supernatants of isolates, and yogurt product made by using it. Those 3 strains were used for the following in vivo tests.

\section{Monitoring the Antioxidant Gene Expression Level in Cell Lines of Caco-2 and HT-29 Co-incubated with LAB by RT-PCR}

Upon the above finding of the antioxidant ability of L. mucosae LMU1001, L. plantarum LPL0302, and L. plantarum LPL0902 in vitro, to ascertain their mechanism at the molecular level, a respective co-incubation

Table 2. Oligonucleotide primer pairs used for real-time PCR on cells

\begin{tabular}{lll}
\hline Product $^{1}$ & Forward primer $\left(5^{\prime}-3^{\prime}\right)$ & Reverse primer $\left(5^{\prime}-3^{\prime}\right)$ \\
\hline$\beta$-Actin & AGCGAGCATCCCCAAAGTT & GGGCACGAAGGCTCATCATT \\
$P R G 1$ & TTTCCTGGCTTTGTGACTCC & ATGCTTTTGGTCCAGCTCC \\
GPX2 & CACACCATCTCTTCAGCCTAGC & CAAGCAATCTGCCTACCTTAGC \\
SOD2 & TCTTCAGCCTGCACTGAAGT & ACTGAAGGTAGTAAGCGTGC \\
BCL2 & GTGTTCCGCGTGATTGAAGAC & CCCCAGAGAAAGAAGAGGAGTTATAA \\
$M T 1 M$ & CCGTCCGGGTGGGCCTA & GCAGCWCTTCTTGCAGGAGG \\
$M T 1 A$ & TTTCCTCCCCTAAGTGTGTGG & TCGGAGATGGGAGATAAGTGG \\
\hline
\end{tabular}

${ }^{1} P R G 1=$ p53-responsive gene $1 ; G P X 2=$ glutathione peroxidase $2 ; S O D 2=$ superoxide dismutase $2 ; B C L 2=$ B cell CLL/lymphoma 2; $M T 1 M=$ metallothionein $1 \mathrm{M} ; M T 1 A=$ metallothionein $1 \mathrm{~A}$. 
A

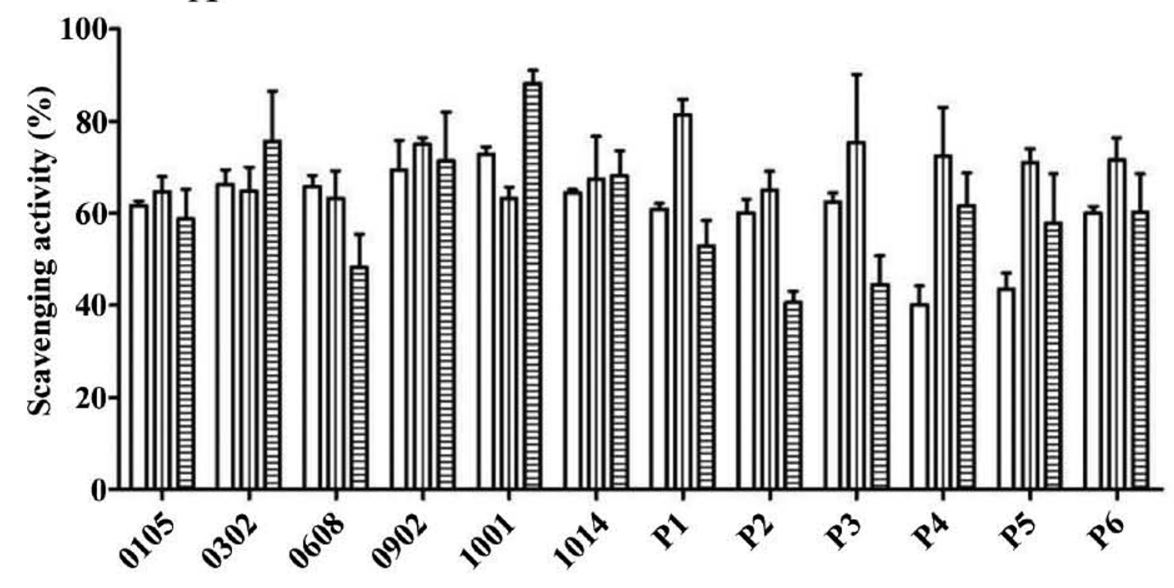

B
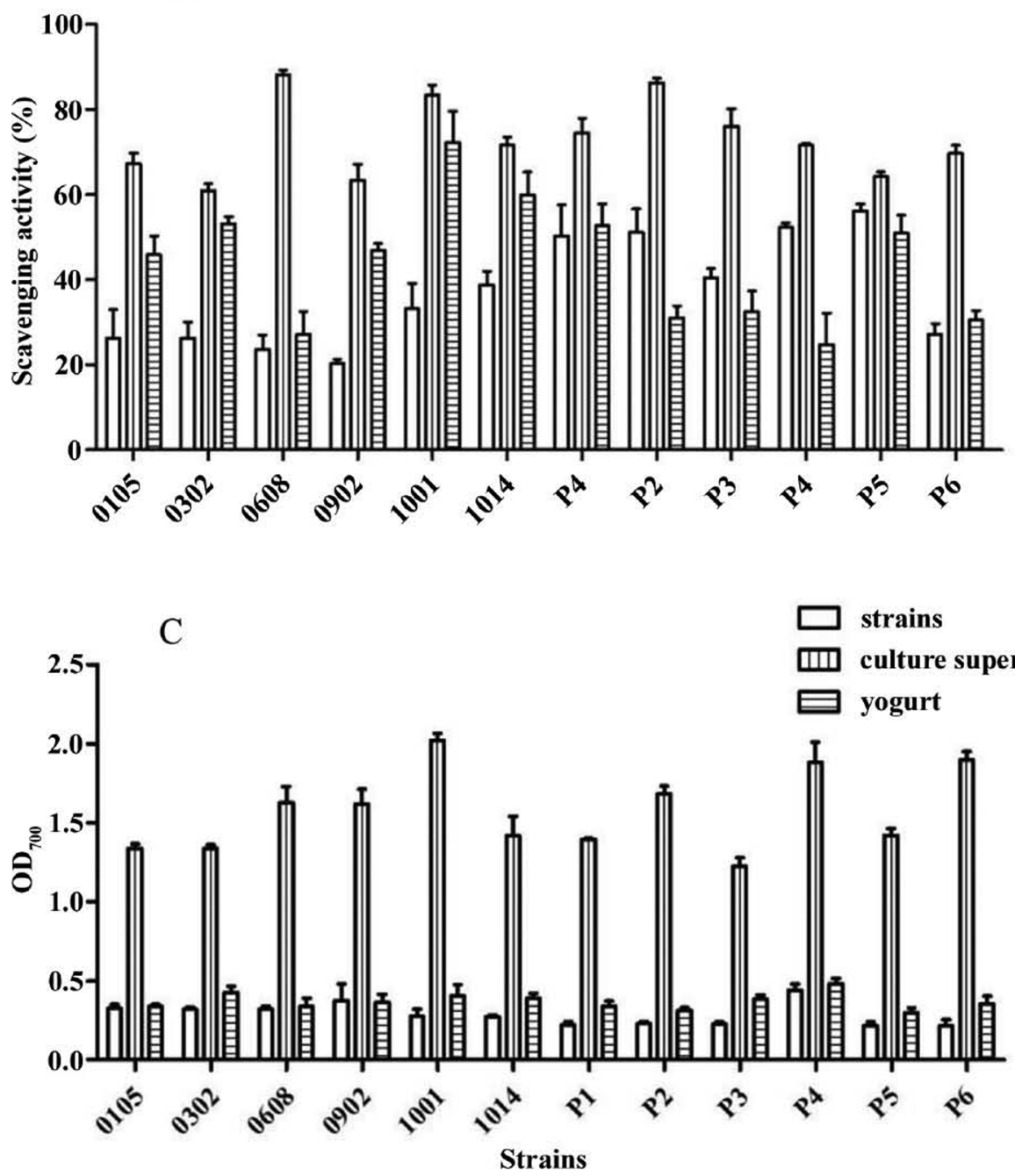

Figure 1. The antioxidant ability of 12 isolates from Gaotian villagers with long lifespans. Scavenging effect of 2,2-diphenyl-1-picrylhydrazyl (DPPH) free radicals (A) and hydroxyl radicals (B); reducing power (measured as optical density at $700 \mathrm{~nm}$; C). $0105=$ Lactobacillus plantarum LPL0105; $0302=$ L. plantarum LPL0302; $0608=$ Lactobacillus fermentum LFE0608; $0902=$ L. plantarum LPL0902; $1001=$ Lactobacillus mucosae LUM1001; P1 = Enterococcus hirae P1; P2 = Lactobacillus salivarius LSAP2; P3 = L. fermentum LFEP3; P4 = Enterococcus faecalis P4; P5 $=$ L. salivarius LSAP5; P6 $=$ L. fermentum LFEP6. The data are presented as means \pm standard deviation. 

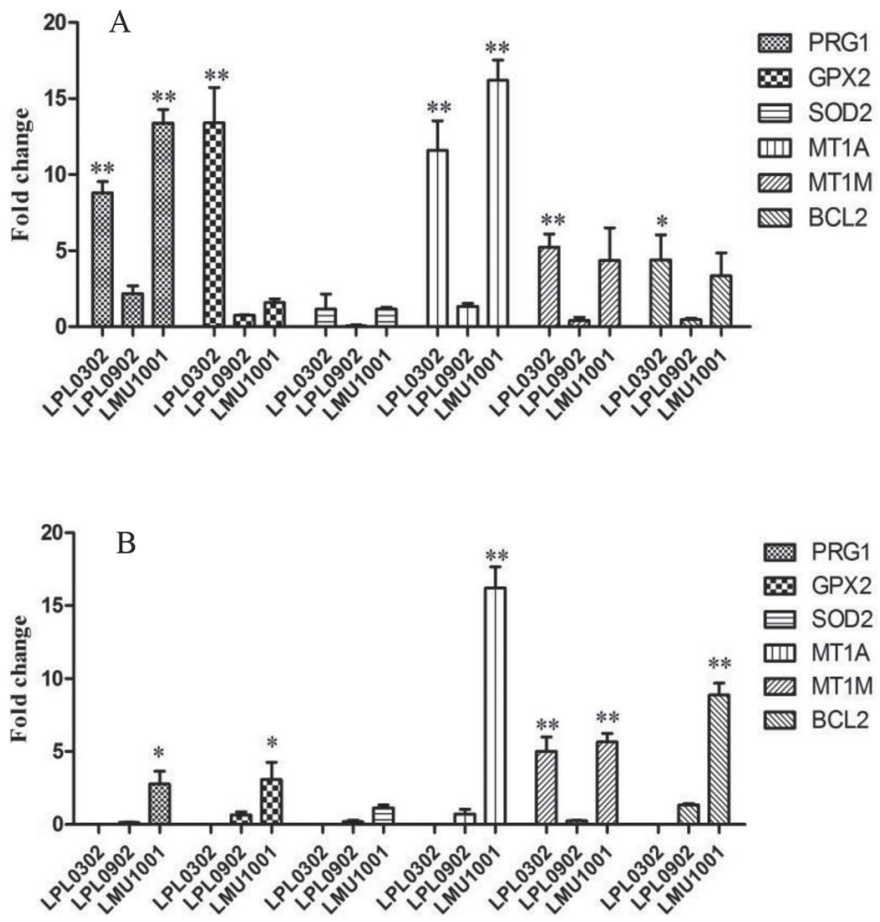

Figure 2. Gene expression of HT-29 (A) and Caco-2 (B) in mRNA level after incubation with Lactobacillus mucosae LMU1001, including PRG1, GPX2, SOD2, MT1A, MT1M, and BCL2. A ratio $>1$ indicated upregulation of gene expression, whereas a ratio $<1$ indicated downregulation. ${ }^{*} P<0.05$ and ${ }^{* *} P<0.01$ : significantly different compared with negative group. The data are presented as means \pm standard deviation.

of that strain with the epithelial cell lines of HT-29 and Caco-2 was designed and a series of RT-PCR assays was performed. As shown in Figure 2, the gene expression level of the independent gene (i.e., PRG1, GPX2, $M T 1 A, M T 1 M$, and BCL2) presented an increasing trend in both cell lines, of which $M T 1 A$ was the highest, followed by $M T 1 M$, and both of them together with GPX2 were highly significant $(P<0.01)$ in Caco-2. The PRG1 and BCL2 were upregulated by L. mucosae LMU1001 either in HT-29 or Caco-2.

\section{Effect of L. mucosae LMU1001 and L. plantarum LPL0302 and LPL0902 on Physiological and Biochemical Index and In Vivo Antioxidant Potential in D-Gal-Induced Aging Mice}

Based on the results of the in vitro tests of the antioxidant ability and antioxidant gene expression level in cell lines, we speculated that L. mucosae LMU1001 might have an anti-aging ability and the D-Gal-induced aging model mice were continuously administered with yogurt fermented by $L$. mucosae LMU1001, and $L$. plantarum LPL0302 and LPL0902 for 1 mo.
Results of BW and organ indices (Table 3) showed no differences in BW, heart, and spleen index among D-Gal model mice, LAB administered mice, and control mice $(P>0.05)$; however, the liver and kidney index of D-Gal model mice was significantly lower $(P<0.05)$ than those of the mice administered with $L$. mucosae LMU1001 $(4.91 \pm 0.23,0.96 \pm 0.24)$ and vitamin $\mathrm{C}$ $(4.23 \pm 0.33,1.16 \pm 0.24)$, respectively, unlike the other 2 L. plantarum. Further, as compared with the vitamin C group, the liver index of L. mucosae LMU1001 group was higher $(P<0.05)$, but the kidney index was not $(P>0.05)$, indicating that L. mucosae LMU1001 has a similar potential to reduce the harmful effect of D-Gal on the liver of mice. Subsequently, liver function reflected by level of ALT, AST, TBIL, and DBIL in the serum was monitored, and results (Figure 3) showed that the level of ALT and AST of L. mucosae LMU1001 deceased significantly $(P<0.05, P<0.01$, respectively $)$, similar to the vitamin $\mathrm{C}$ group $(P<0.01)$, when compared with D-Gal group, whereas 2 other LAB strains presented a nonsignificant difference. On the other hand, no differences were found in the index of TBIL and DBIL among all groups $(P>0.05)$. Results of glucose and lipid metabolism of serum (Figure 3) exhibited that GLU level increased significantly in all the groups, except the normal control group, when compared with the D-Gal group. For T-CHOL, only L. mucosae LUM1001 and vitamin C increased significantly when compared with the D-Gal group $(P<0.05)$. For TG, only vitamin $\mathrm{C}$ and $L$. plantarum LPL0302 significantly decreased their level when compared with the D-Gal group $(P<0.01, P<0.05$, respectively; Figure $4 \mathrm{C})$. Results of LAB on the level of CREA, UREA, and UA in serum showed no effect, except that L. plantarum LPL0302 lowered the UA level.

\section{In Vivo Test of Antioxidant Ability of Yogurt Fermented by L. mucosae LMU1001 and L. plantarum LPL0302 and LPL0902 in $D$-Gal-Induced Aging Mice}

To further confirm in vitro antioxidant ability of the $3 \mathrm{LAB}$, the level of GSH-PX, T-SOD, and MDA in the serum and liver of D-Gal-induced aging mice was monitored. As shown in Figure 5, only L. mucosae LMU1001 significantly increased the level of GSH-PX and lowered the MDA in the serum. When compared with the vitamin C group, this strain showed the same trend as in vivo antioxidant tests. Similar to serum tests, for the level GSH-PX, T-SOD, and MDA in the liver (Figure 6), only L. mucosae LMU1001 demonstrated a significant increase in potential for T-SOD. When compared with vitamin $\mathrm{C}$, that strain exhibited the 

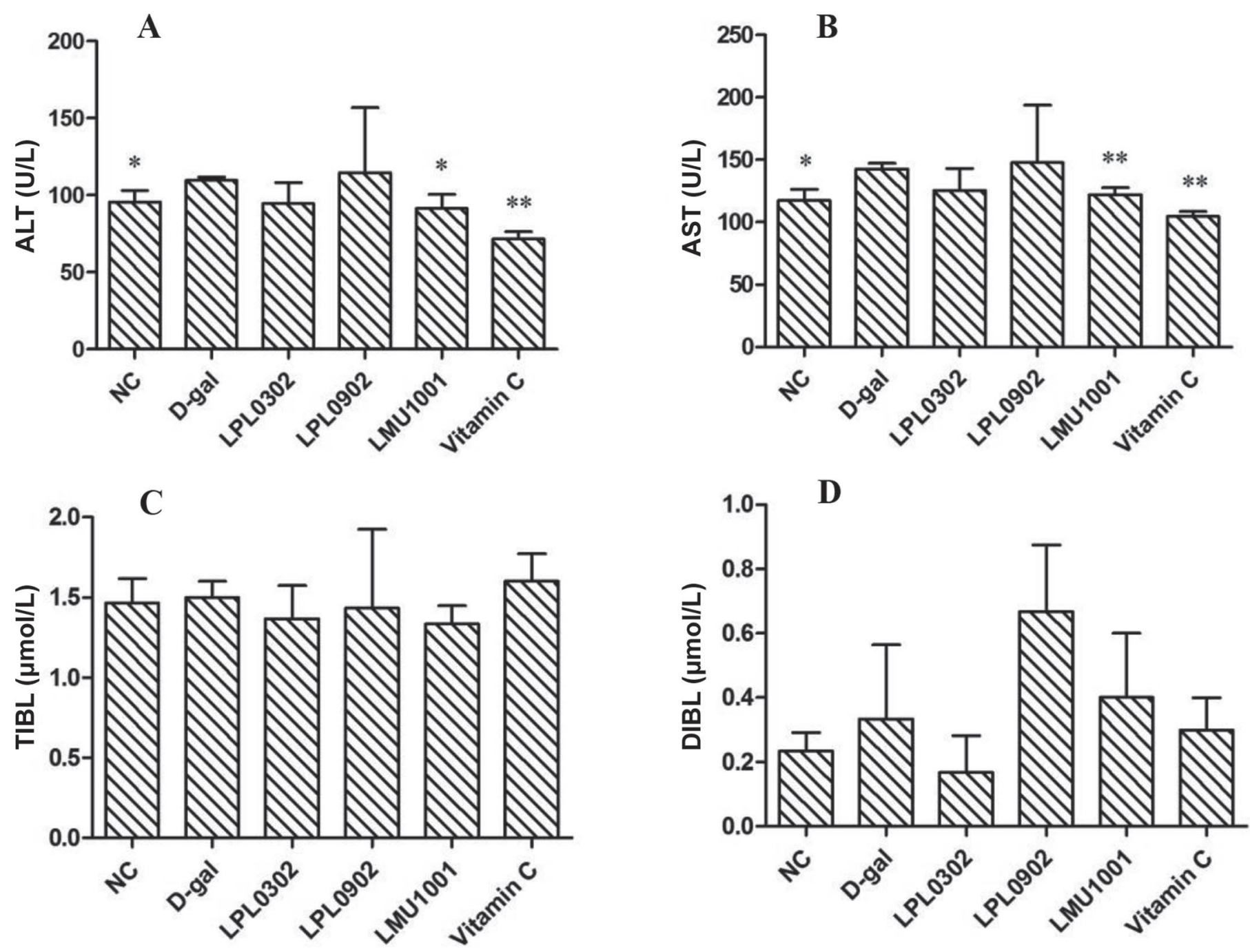

Figure 3. Biochemical analysis of serum of D-galactose (D-Gal)-induced mice administered with yogurt made by using Lactobacillus mucosae LMU1001, and Lactobacillus plantarum LPL0902 and LPL0302. The negative control group (NC) was injected subcutaneously with physiological saline and administered skim milk via gastric gavage. (A) Alanine aminotransferase (ALT), (B) aspartate aminotransferase (AST), (C) total bilirubin (TBIL), and (D) direct bilirubin (DBIL). The data are presented as means \pm standard deviation $(\mathrm{n}=10)$. ${ }^{*} P<0.05$ and ${ }^{* *} P<0.01$ : significantly different compared with D-Gal model mice.

Table 3. Effect of administered strains on BW and organ index of mice ${ }^{1}$

\begin{tabular}{|c|c|c|c|c|c|c|}
\hline \multirow[b]{2}{*}{ Group } & \multicolumn{2}{|c|}{ BW (g) } & \multicolumn{4}{|c|}{ Organ index ${ }^{2}$} \\
\hline & $0 \mathrm{wk}$ & $7 \mathrm{wk}$ & Liver & Heart & Spleen & Kidney \\
\hline D-Gal & $22.89 \pm 1.68$ & $34.54 \pm 1.28$ & $5.69 \pm 0.28$ & $0.54 \pm 0.06$ & $0.92 \pm 0.16$ & $1.32 \pm 0.03$ \\
\hline D-Gal + LPL0302 & $22.54 \pm 2.02$ & $35.65 \pm 0.87$ & $4.90 \pm 0.82$ & $0.46 \pm 0.02$ & $0.67 \pm 0.42$ & $1.18 \pm 0.14$ \\
\hline D-Gal + LMU1001 & $23.13 \pm 1.78$ & $36.10 \pm 3.09$ & $4.91 \pm 0.23^{\mathrm{a}}$ & $0.49 \pm 0.01$ & $0.48 \pm 0.27$ & $0.96 \pm 0.24^{\mathrm{a}}$ \\
\hline D-Gal + LPL0902 & $22.98 \pm 2.49$ & $35.50 \pm 1.23$ & $5.28 \pm 0.98$ & $0.45 \pm 0.01$ & $0.43 \pm 0.14$ & $1.06 \pm 0.06$ \\
\hline
\end{tabular}

${ }^{\mathrm{a}} P<0.05$.

${ }^{\mathrm{b}} P<0.01$ compared with D-galactose (D-Gal) model mice.

${ }^{1}$ The data presented are means \pm standard deviation $(\mathrm{n}=10)$. LMU1001 $=$ Lactobacillus mucosae LMU1001, and LPL0902 and LPL0302 $=$ Lactobacillus plantarum LPL0902 and LPL0302.

${ }^{2}$ Organ index $=$ weight of $\mathrm{organ} / \mathrm{BW} \times 100$. 

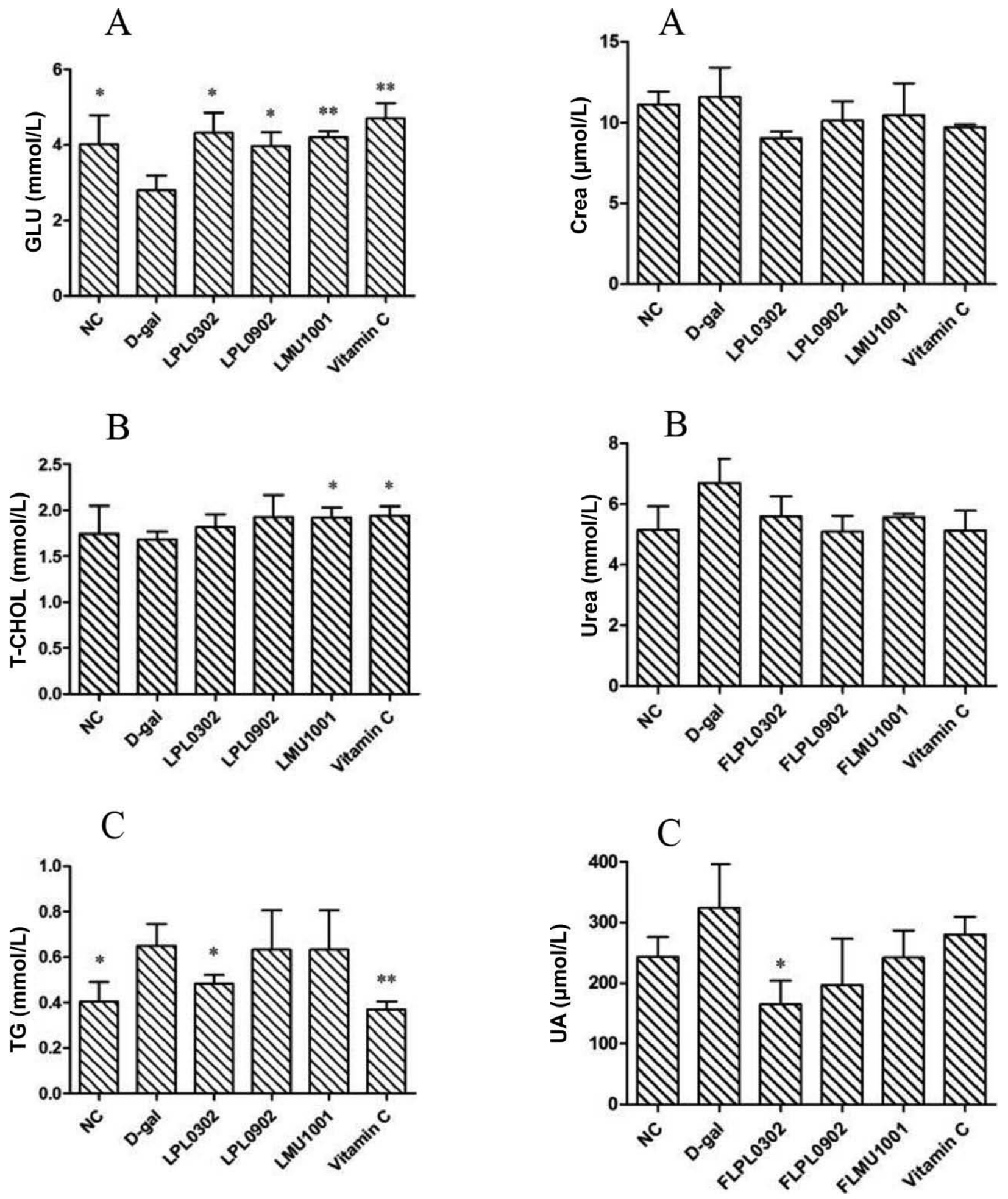

Figure 4. Glucose and lipid metabolism reflected by serum in Dgalactose (D-Gal)-induced mice fed yogurt with Lactobacillus mucosae LMU1001, and Lactobacillus plantarum LPL0902 and LPL0302. The negative control group (NC) was injected subcutaneously with physiological saline and administered skim milk via gastric gavage. (A) Blood glucose (GLU), (B) total cholesterol (T-CHOL), and (C) triglyceride $(\mathrm{TG})$. The data are presented as means \pm standard deviation $(\mathrm{n}=10) .{ }^{*} P<0.05$ and ${ }^{* *} P<0.01$ : significantly different compared with D-Gal model mice.

Figure 5. The level of (A) creatinine, (B) urea, and (C) uric acid in serum of D-galactose (D-Gal)-induced mice fed yogurt with Lactobacillus mucosae LMU1001, and Lactobacillus plantarum LPL0902 and LPL0302. The negative control group (NC) was injected subcutaneously with physiological saline and administered skim milk via gastric gavage. The data are presented as means \pm standard deviation $(\mathrm{n}=10)$. ${ }^{*} P<0.05$ and ${ }^{* *} P<0.01$ : significantly different compared with D-Gal model mice. 
Serum
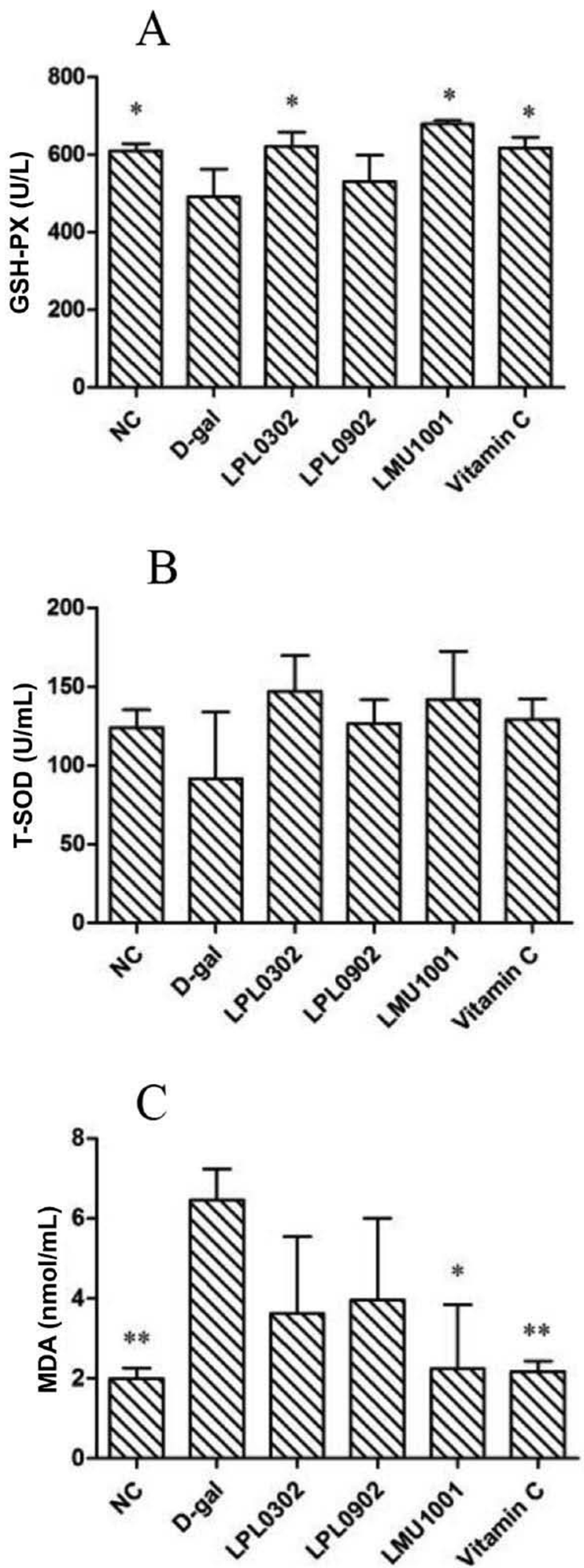

Liver
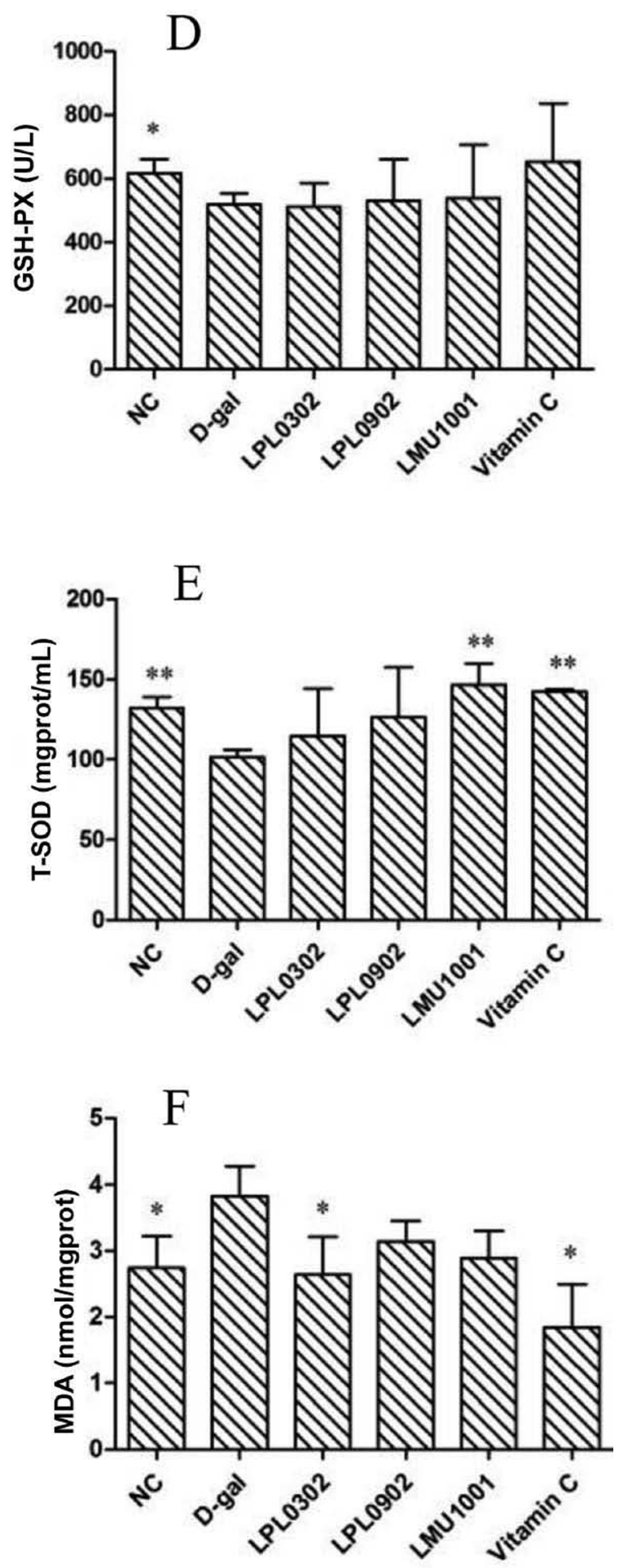

Figure 6. Effect of strains and vitamin $\mathrm{C}$ on the activity of glutathione peroxidase (GSH-PX) and total superoxide dismutase (T-SOD) as well as malondialdehyde (MDA) level in serum (A-C) and liver (D-E) of D-galactose (D-Gal)-induced mice fed yogurt with Lactobacillus mucosae LMU1001, and Lactobacillus plantarum LPL0902 and LPL0302. The negative control group (NC) was injected subcutaneously with physiological saline and administered skim milk via gastric gavage. $\mathrm{A}$ and $\mathrm{D}=\mathrm{GSH}-\mathrm{PX}$ activity; $\mathrm{B}$ and $\mathrm{E}=\mathrm{T}-\mathrm{SOD}$ activity; $\mathrm{C}$ and $\mathrm{F}=\mathrm{MDA}$ level. The data are presented as means \pm standard deviation $(\mathrm{n}=10) .{ }^{*} P<0.05$ and ${ }^{* *} P<0.01$ : significantly different compared with D-Gal model mice. 


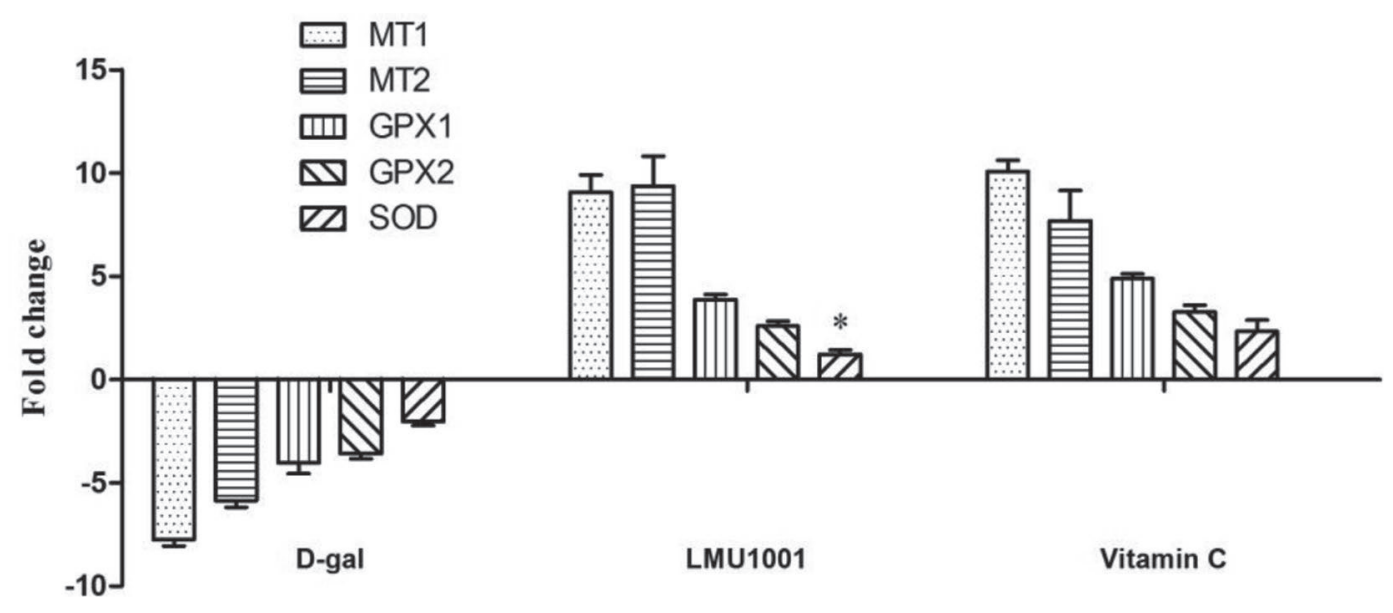

Figure 7. Gene expression of mRNA in the intestine tract of D-galactose (D-Gal)-induced aging mice, including MT1, MT2, GPX1, GPX2, and $S O D$. A ratio greater than 1 indicated upregulation of gene expression, whereas a ratio below 1 indicated downregulation. The data are presented as means \pm standard deviation. ${ }^{*} P<0.05$ : significantly different compared with vitamin $\mathrm{C}$ group.

same potential for enhancing the antioxidant ability in D-Gal-induced aging mice.

\section{Verification of the Regulation of Antioxidant Gene Expression in the Intestine of D-Gal-Induced Aging Mice Administered Yogurt Fermented by L. mucosae LMU1001}

Furthermore, using vitamin $\mathrm{C}$ as a positive control, the antioxidant gene expression level of D-Gal-induced aging mice administered with L. mucosae LMU1001 was detected by RT-PCR. As shown in Figure 7, all of the genes expression inducing MT1, MT2, GPX1, GPX2, and $S O D$ were upregulated in the groups of $L$. mucosae LUM1001 and vitamin C, whereas those genes were downregulated in the D-Gal model mice. The levels of MT1 and MT2 increased as high as 8-fold. Lactobacillus mucosae LMU1001 and vitamin C showed a similar efficiency to improve the antioxidant activity in D-Galinduced aging mice, except for $S O D$ gene expression.

\section{DISCUSSION}

Several studies have reported probiotic functions of LAB due to their antioxidant potential ( $\mathrm{Li}$ et al., 2014b; Persichetti et al., 2014; Dilna et al., 2015). In this study, 12 isolates of the 82 isolates from Gaotian villagers with long lifespans were tested for their in vitro and in vivo antioxidant potential based on the contribution of cell counts, supernatants, as well as yogurts made from those isolates to examine their potential application. Three of the isolates, namely, $L$. mucosae LMU1001 and L. plantarum LPL0302 and LPL0902, were screened out for their antioxidant abil- ity using scavenging of DPPH free radical and hydroxyl radical or their reducing power. Based on the results, $L$. mucosae LMU1001 was found to be the best candidate. A similar organism has been isolated from humans and their biological functionalities were reported (Roos et al., 2000; London et al., 2014). Previously, L. mucosae were detected in feces and mucosa-associated microbiota of short bowel syndrome patients (Joly et al., 2010) and from strongly enriched mucus in a dynamic gut model (Van den Abbeele et al., 2012).

Only a few studies report a systematic in vitro and in vivo evaluation of antioxidant activity. Upon finding significantly higher antioxidant potential strains (i.e., L. mucosae LMU1001 and L. plantarum LPL0302 and LPL0902), we report that L. mucosae LMU1001 decreased the level of ALT, AST, T-CHOL, and Glu, with no effect on BW and CREA. Theoretically, in vivo damage of organs by free radicals is usually reflected in the abnormal expression of organ indices and biomarkers (e.g., ATL, AST, and CREA) in the serum of aged mice (Zhang et al., 2009). Alanine transaminase and AST are the most important enzymes for judging hepatic metabolism (Mera et al., 2008; Ceriotti et al., 2010). Our results demonstrated that ALT and AST decreased significantly in L. mucosae LMU1001 groups, indicating their protective effect on liver. To the best of our limited knowledge, no studies have reported the effect of LAB on those 3 indices in D-Gal-induced aging mice. Only plant antioxidant materials [e.g., Korean red ginseng water extract (Ramesh et al., 2012), blueberry (Coban et al., 2014), and Troxerutin (Zhang et al., 2009)] were found to have a similar improvement in D-Gal-induced mice. Remarkably, L. mucosae LMU1001 was reported to have similar in vivo antioxidant ability 
as vitamin $\mathrm{C}$ as supported by regulation in the level of GSH-PX, T-SOD, and MDA in the serum.

To ascertain the up- and downregulation of antioxidant-related genes in vivo and in vitro, we selected metallothioneins, superoxide dismutase, and GSH-PX as the target. The MT1A and MT1M are functional members of the metallothionein superfamily, which are small cysteine-rich intercellular proteins, and protect cells against oxidative stress by virtue of their freeradical-scavenging capacity and their inhibitory effect on the activity of ROS-producing enzymes (Schulkens et al., 2014). The $S O D$ is a ubiquitously expressed mitochondrial antioxidant enzyme that is essential for mammalian life. The GPX2 gene, which encodes a GSH-PX, may be used to regulate the intracellular hydroperoxide level in the gastrointestinal tract (Yan and Chen, 2006). We found that GPX2, MT1A, and $M T 1 M$ were positively upregulated by $L$. mucosae LMU1001 either in cell lines of HT-29 and Caco-2 or D-Gal-induced model mice. Our results indicated that L. mucosae LMU1001 might be a potential strain for enhancing their antioxidant ability for health promotion. Our results indicated that L. mucosae LMU1001 might be associated with cell differentiation and the inhibition of tumors.

\section{CONCLUSIONS}

Lactobacillus mucosae LMU1001, originally isolated from a Gaotian villager with a long lifespan, was proven to have strong antioxidant potential through a systematic evaluation in vitro and in vivo. Out of 12 strains, cells, supernatants, and fermented yogurt of L. mucosae LMU1001 presented a higher activity of scavenging free radical and total reducing power. Lactobacillus mucosae LMU1001 increased antioxidant ability in D-Galinduced oxidant stressed mice by increasing the activity of GSH-PX and T-SOD, decreasing the level of MDA, and ameliorating the function of the liver through decreasing metabolic enzymes (e.g., ALT, AST, and T-SOD). Furthermore, L. mucosae LMU1001 enhanced the expression of GPX2, MT1A, and $M T 1 M$ in either cell lines of HT-29 and Caco-2, or D-Gal-induced aging mice. The results suggested that L. mucosae LMU1001 could be a probiotic candidate, which could be applied in nutraceutical and dairy products to improve the antioxidant status of the host.

\section{ACKNOWLEDGMENTS}

This project was sponsored by the Chinese High-Tech R\&D (863) program (2014AA022209), the National Natural Science Foundation of China (NSF31170091, 31260363, 81160494, 31000048), Ganpo Talent 555
Engineering Project of Jiangxi Province, and the Academic and Technical Leaders Training Program for Major Subjects of Jiangxi Province (2009).

\section{REFERENCES}

Arasu, M. V., N. A. Al-Dhabi, T. S. Rejiniemon, K. D. Lee, V. A. J. Huxley, D. H. Kim, V. Duraipandiyan, P. Karuppiah, and K. C. Choi. 2014. Identification and characterization of Lactobacillus brevis $\mathrm{P} 68$ with antifungal, antioxidant and probiotic functional properties. Indian J. Microbiol. 55:19-28.

Biagi, E., M. Candela, F.-P. Martin, S. Collino, C. Franceschi, and P. Brigidi. 2015. Metabonomics and Gut Microbial Paradigm in Healthy Aging. Pages 169-184 in Metabonomics and Gut Microbiota in Nutrition and Disease. Springer, New York, NY.

Ceriotti, F., J. Henny, J. Queralto, S. Ziyu, Y. Ozarda, B. Chen, J. C. Boyd, M. Panteghini, and IFCC Committee on Reference Intervals and Decision Limits (C-RIDL), and Committee on Reference Systems for Enzymes (C-RSE). 2010. Common reference intervals for aspartate aminotransferase (AST), alanine aminotransferase (ALT) and gamma-glutamyl transferase (GGT) in serum: Results from an IFCC multicenter study. Clinical Chemistry and Laboratory Medicine: CCLM/FESCC 48:1593-1601.

Coban, J., E. Betul-Kalaz, C. Kucukgergin, A. F. Aydin, I. Dogan-Ekici, S. Dogru-Abbasoglu, and M. Uysal. 2014. Blueberry treatment attenuates D-galactose-induced oxidative stress and tissue damage in rat liver. Geriatr. Gerontol. Int. 14:490-497.

Deelen, J., M. Beekman, H. W. Uh, L. Broer, K. L. Ayers, Q. Tan, Y. Kamatani, A. M. Bennet, R. Tamm, S. Trompet, D. F. Guethbjartsson, F. Flachsbart, G. Rose, A. Viktorin, K. Fischer, M. Nygaard, H. J. Cordell, P. Crocco, E. B. van den Akker, S. Bohringer, Q. Helmer, C. P. Nelson, G. I. Saunders, M. Alver, K. Andersen-Ranberg, M. E. Breen, R. van der Breggen, A. Caliebe, M. Capri, E. Cevenini, J. C. Collerton, S. Dato, K. Davies, I. Ford, J. Gampe, P. Garagnani, E. J. de Geus, J. Harrow, D. van Heemst, B. T. Heijmans, F. A. Heinsen, J. J. Hottenga, A. Hofman, B. Jeune, P. V. Jonsson, M. Lathrop, D. Lechner, C. Martin-Ruiz, S. E. McNerlan, E. Mihailov, A. Montesanto, S. P. Mooijaart, A. Murphy, E. A. Nohr, L. Paternoster, I. Postmus, F. Rivadeneira, O. A. Ross, S. Salvioli, N. Sattar, S. Schreiber, H. Stefansson, D. J. Stott, H. Tiemeier, A. G. Uitterlinden, R. G. Westendorp, G. Willemsen, N. J. Samani, P. Galan, T. I. Sorensen, D. I. Boomsma, J. W. Jukema, I. M. Rea, G. Passarino, A. J. de Craen, K. Christensen, A. Nebel, K. Stefansson, A. Metspalu, P. Magnusson, H. Blanche, L. Christiansen, T. B. Kirkwood, C. M. van Duijn, C. Franceschi, J. J. Houwing-Duistermaat, and P. E. Slagboom. 2014. Genome-wide association meta-analysis of human longevity identifies a novel locus conferring survival beyond 90 years of age. Hum. Mol. Genet. 23:4420-4432.

Dilna, S. V., H. Surya, R. G. Aswathy, K. V. Kontham, D. N. Sakthikumar, A. Pandey, and K. M. Nampoothiri. 2015. Characterization of an exopolysaccharide with potential health-benefit properties from a probiotic Lactobacillus plantarum $\mathrm{RJF}_{4}$. LWT-Food Science and Technology. 64:1179-1186.

Feng, Y., J. Gong, H. Yu, Y. Jin, J. Zhu, and Y. Han. 2010. Identification of changes in the composition of ileal bacterial microbiota of broiler chickens infected with Clostridium perfringens. Vet. Microbiol. 140:116-121.

Ferreira, I. C. F. R., P. Baptista, M. Vilas-Boas, and L. Barros. 2007. Free-radical scavenging capacity and reducing power of wild edible mushrooms from northeast Portugal: Individual cap and stipe activity. Food Chem. 100:1511-1516.

Joly, F., C. Mayeur, A. Bruneau, M. L. Noordine, T. Meylheuc, P. Langella, B. Messing, P. H. Duee, C. Cherbuy, and M. Thomas. 2010. Drastic changes in fecal and mucosa-associated microbiota in adult patients with short bowel syndrome. Biochimie 92:753-761.

Kanno, T., T. Kuda, C. An, H. Takahashi, and B. Kimura. 2012. Radical scavenging capacities of saba-narezushi, Japanese fermented chub mackerel, and its lactic acid bacteria. LWT Food Sci. Technol. (Campinas.) 47:25-30. 
LeBlanc, J. G., S. del Carmen, A. Miyoshi, V. Azevedo, F. Sesma, P. Langella, L. G. Bermudez-Humaran, L. Watterlot, G. Perdigon, and A. de Moreno de LeBlanc. 2011. Use of superoxide dismutase and catalase producing lactic acid bacteria in TNBS induced Crohn's disease in mice. J. Biotechnol. 151:287-293.

Li, S., R. Huang, N. P. Shah, X. Tao, Y. Xiong, and H. Wei. 2014a. Antioxidant and antibacterial activities of exopolysaccharides from Bifidobacterium bifidum WBIN03 and Lactobacillus plantarum R315. J. Dairy Sci. 97:7334-7343.

Li, S., and N. P. Shah. 2014. Antioxidant and antibacterial activities of sulphated polysaccharides from Pleurotus eryngii and Streptococcus thermophilus ASCC 1275. Food Chem. 165:262-270.

Li, W., J. Ji, X. Chen, M. Jiang, X. Rui, and M. Dong. 2014b. Structural elucidation and antioxidant activities of exopolysaccharides from Lactobacillus helveticus MB2-1. Carbohydr. Polym. 102:351359 .

London, L., N. Price, P. Ryan, L. Wang, M. Auty, G. Fitzgerald, C. Stanton, and R. Ross. 2014. Characterization of a bovine isolate Lactobacillus mucosae DPC 6426 which produces an exopolysaccharide composed predominantly of mannose residues. J. Appl. Microbiol. 117:509-517.

Makarova, K., A. Slesarev, Y. Wolf, A. Sorokin, B. Mirkin, E. Koonin, A. Pavlov, N. Pavlova, V. Karamychev, and N. Polouchine. 2006. Comparative genomics of the lactic acid bacteria. Proc. Natl. Acad. Sci. USA 103:15611-15616.

Marazza, J. A., M. A. Nazareno, G. S. de Giori, and M. S. Garro. 2012. Enhancement of the antioxidant capacity of soymilk by fermentation with Lactobacillus rhamnosus. J. Funct. Foods 4:594-601.

Mera, J. R., B. Dickson, and M. Feldman. 2008. Influence of gender on the ratio of serum aspartate aminotransferase (AST) to alanine aminotransferase (ALT) in patients with and without hyperbilirubinemia. Dig. Dis. Sci. 53:799-802.

Persichetti, E., A. De Michele, M. Codini, and G. Traina. 2014. Antioxidative capacity of Lactobacillus fermentum LF31 evaluated in vitro by oxygen radical absorbance capacity assay. Nutrition 30:936-938.

Prather, A. A., E. S. Epel, J. Arenander, L. Broestl, B. I. Garay, D. Wang, and D. B. Dubal. 2015. Longevity factor klotho and chronic psychological stress. Transl. Psychiatry 5:e585.

Ramesh, T., S. W. Kim, S. Y. Hwang, S. H. Sohn, S. K. Yoo, and S. K. Kim. 2012. Panax ginseng reduces oxidative stress and restores antioxidant capacity in aged rats. Nutr. Res. 32:718-726.

Roos, S., F. Karner, L. Axelsson, and H. Jonsson. 2000. Lactobacillus mucosae sp. nov., a new species within vitromucus-binding ac- tivity isolated from pig intestine. Int. J. Syst. Evol. Microbiol. 50:251-258.

Schulkens, I. A., K. C. Castricum, E. M. Weijers, P. Koolwijk, A. W. Griffioen, and V. L. Thijssen. 2014. Expression, regulation and function of human metallothioneins in endothelial cells. J. Vasc. Res. 51:231-238.

Song, X., M. Bao, D. Li, and Y. M. Li. 1999. Advanced glycation in D-galactose induced mouse aging model. Mech. Ageing Dev. 108:239-251.

Van den Abbeele, P., S. Roos, V. Eeckhaut, D. A. MacKenzie, M. Derde, W. Verstraete, M. Marzorati, S. Possemiers, B. Vanhoecke, F. Van Immerseel, and T. Van de Wiele. 2012. Incorporating a mucosal environment in a dynamic gut model results in a more representative colonization by lactobacilli. Microb. Biotechnol. 5:106-115.

Woo, J. Y., W. Gu, K. A. Kim, S. E. Jang, M. J. Han, and D. H. Kim. 2014. Lactobacillus pentosus var. plantarum C29 ameliorates memory impairment and inflammaging in a D-galactose-induced accelerated aging mouse model. Anaerobe 27:22-26.

Yan, W., and X. Chen. 2006. GPX2, a direct target of p63, inhibits oxidative stress-induced apoptosis in a p53-dependent manner. J. Biol. Chem. 281:7856-7862.

Yang, H. Y., S. L. Liu, S. A. Ibrahim, L. Zhao, J. L. Jiang, W. F. Sun and F. Z. Ren. 2009. Oral administration of live Bifidobacterium substrains isolated from healthy centenarians enhanced immune function in BALB/c mice. Nutr. Res. 29:281-289.

Yu, X., X. Wu, L. Qiu, D. Wang, M. Gan, X. Chen, H. Wei, and F. $\mathrm{Xu}$. 2015. Analysis of the intestinal microbial community structure of healthy and long-living elderly residents in Gaotian Village of Liuyang City. Appl. Microbiol. Biotechnol.99:9085-9095.

Zhang, Y., R. Du, L. Wang, and H. Zhang. 2010. The antioxidative effects of probiotic Lactobacillus casei Zhang on the hyperlipidemic rats. Eur. Food Res. Technol. 231:151-158.

Zhang, Z. F., S. H. Fan, Y. L. Zheng, J. Lu, D. M. Wu, Q. Shan, and B. Hu. 2009. Troxerutin protects the mouse liver against oxidative stress-mediated injury induced by D-galactose. J. Agric. Food Chem. 57:7731-7736.

Zhao, L., W. Xu, S. A. Ibrahim, J. Jin, J. Feng, J. Jiang, J. Meng, and F. Ren. 2011. Effects of age and region on fecal microflora in elderly subjects living in Bama, Guangxi, China. Curr. Microbiol. 62:64-70. 